\title{
ACCELERATOR RESEARCH STUDIES
}

For the period June 1, 1994 to May 31, 1995

Submitted to

U.S. Department of Energy

Submitted by Institute for Plasma Research

University of Maryland, College Park

Martin Reiser, Project Director

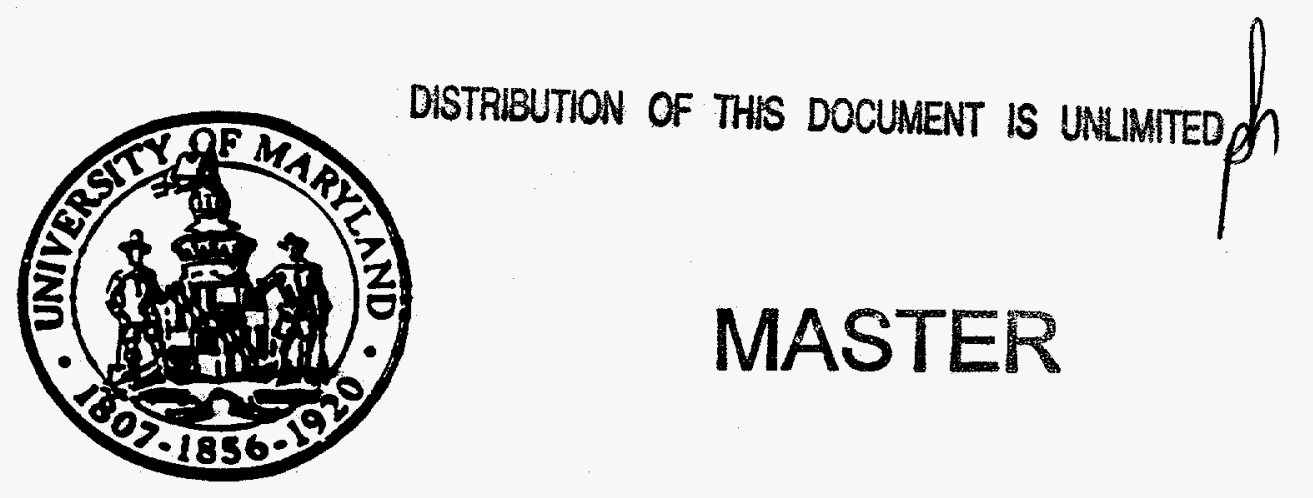

\section{UNIVERSITY OF MARYLAND}

INSTITUTE FOR PLASMA RESEARCH 


\section{DISCLAIMER}

This report was prepared as an account of work sponsored by an agency of the United States Government. Neither the United States Government nor any agency thereof, nor any of their employees, makes any warranty, express or implied, or assumes any legal liability or responsibility for the accuracy, completeness, or usefulness of any information, apparatus, product, or process disclosed, or represents that its use would not infringe privately owned rights. Reference herein to any specific commercial product, process, or service by trade name, trademark, manufacturer, or otherwise does not necessarily constitute or imply its endorsement, recommendation, or favoring by the United States Government or any agency thereof. The views and opinions of authors expressed herein do not necessarily state or reflect those of the United States Government or any agency thereof. 


\section{DISCLAIMER}

Portions of this document may be illegible electronic image products. Images are produced from the best available original document. 


\section{SUMMARY}

The Accelerator Research Studies program at the Univeristy of Maryland, sponsored by the Department of Energy under contract number DEFG05-91ER40642, has completed the third year of its three-year funding cycle and an additional one-year, no-cost extension. The program consisted of the following three tasks:

Task A: Study of the Transport and Longitudinal Compression of Intense, High-Brightness Beams;

Task B: Study of High-Brightness Beam Generation in Pseudospark Devices;

Task C: Study of a Gyroklystron High-Power Microwave Source for Linear Colliders.

In Task $\mathrm{A}$, the major recent achievements were:

1) halo observation and analysis in a mismatched beam with nonlinear space-charge forces (multiple-beam experiment);

2) longitudinal expansion and compression of bunches with parabolic and retangular pulse shape;

3) generation, for the first time, of single space-charge waves in the form of local perturbations in a space-charge dominated beam;

4) study of space-charge wave reflection at the bunch ends;

5) measurement of the "g-factor" for longitudinal perturbations;

6) experimental demonstration of longitudinal instability in a resistive-wall channel and determination of the growth rates and amplitude change of localized perturbations;

7) theoretical studies of the two-temperature thermal beam model and numerical calculations of beam profiles and image effects ( $\mathrm{g}$-factor) for ellipsoidal bunched beams in a circular pipe;

8) completion of book manuscript, "Theory and Design of Charged Particle Beams," by M. Reiser, published in Wiley \& Sons Series on Beam Physics and Accelerator Technology in September 1994.

In Task B, the major recent achievements were:

1) measurement of the time-resolved energy spectrum of the electron beam produced by a low energy ( 25 to $50 \mathrm{keV}$ ) pseudospark including post-acceleration of the electron beam by a small induction module; 
2) successful operation of a pseudospark electron beam source in a $200-\mathrm{kV}$ pulsed-power system and preliminary measurements of the emittance of the high-energy beam component.

In Task $\mathrm{C}$, the major recent achievements were:

1) successful operation of a two-cavity gyroklystron experiment at $19.7 \mathrm{GHz}$, the second harmonic of the cyclotron frequency, with peak power of $31 \mathrm{MW}$ and $28 \%$ efficiency a historic first;

2) improvement of the EGUN code to include the axial diamagnetic self field of the beam which, we expect, will provide better agreement between computer results and experiment;

3) study of a "gyrotwystron" modification of the gyroklystron in which the output cavity is replaced by a traveling-wave section and which is expected to improve efficiency;

4) completion of the design for a new electron gun with higher beam power $(720 \mathrm{~A}$, $500 \mathrm{kV}$ ), and for operation with a coaxial circuit; the purchase order has been placed with Varian. 


\section{Contents}

Task A: Study of the Transport and Longitudinal Compression of Intense, High-Brightness Beams

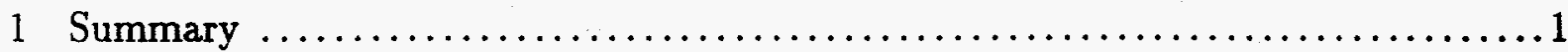

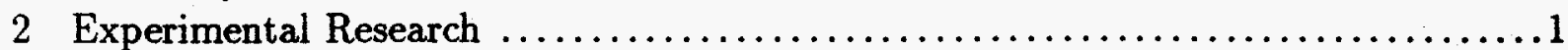

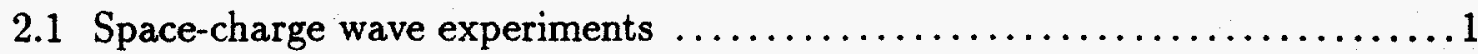

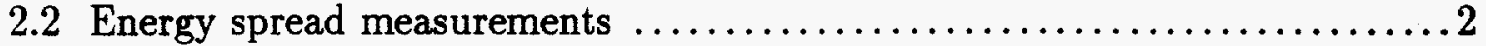

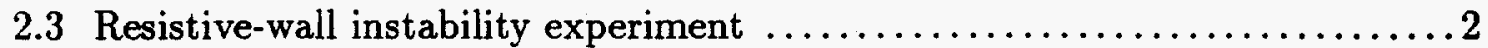

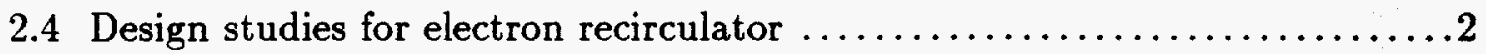

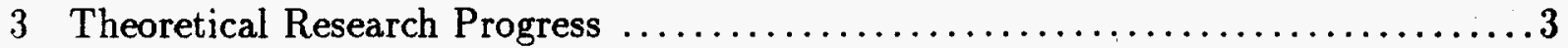

3.1 Theory and design of charged particle beams $\ldots \ldots \ldots \ldots \ldots \ldots \ldots \ldots \ldots, \ldots \ldots$

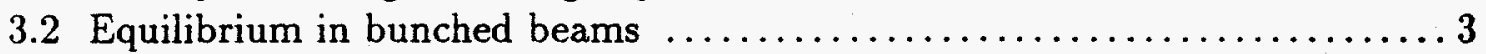

3.3 Design of optimal beam transport and matching systems $\ldots \ldots \ldots \ldots \ldots \ldots . .3$

3.4 Related research at the Naval Research Laboratory $\ldots \ldots \ldots \ldots \ldots \ldots . \ldots 3$

4 Papers and Presentations Resulting from this Research $\ldots \ldots \ldots \ldots \ldots \ldots \ldots \ldots \ldots$

Task B: Study of High-Brightness Beam Generation in Pseudospark Devices

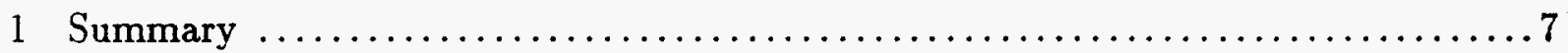

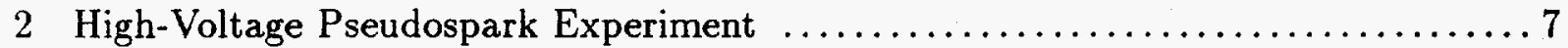

2.1 Long pulse with current limiting resistors $\ldots \ldots \ldots \ldots \ldots \ldots \ldots \ldots \ldots \ldots \ldots$

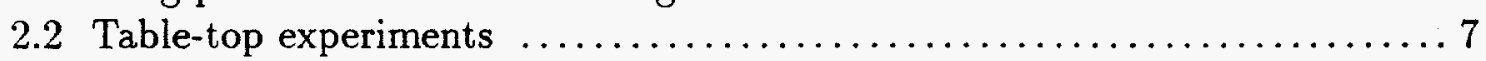

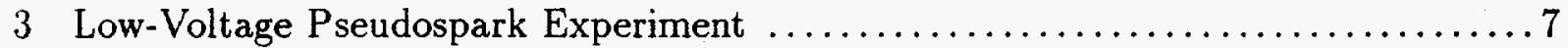

3.1 Study on pseudospark breakdown voltage $\ldots \ldots \ldots \ldots \ldots \ldots \ldots \ldots \ldots \ldots . \ldots \ldots$

3.2 Post-acceleration and propagation of pseudospark-produced electron beam .8

4 Papers and Presentations Resulting from this Research $\ldots \ldots \ldots \ldots \ldots \ldots \ldots \ldots$

Task C: Study of Microwave Sources and Parameter Scaling for HighFrequency $\mathrm{TeV}$ Linear Colliders

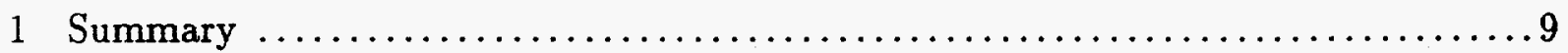

2 Theoretical Analysis ............................................... 9

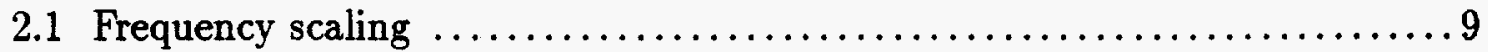

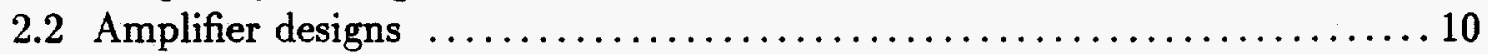

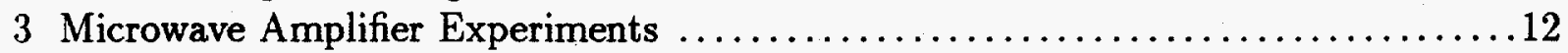

$4 \quad 100$ MW System Design and Construction .............................. 12

5 Papers and Presentations Resulting from this Research $\ldots \ldots \ldots \ldots \ldots \ldots \ldots \ldots \ldots$ 


\section{Task A Progress Report \\ Study of the Transport and Longitudinal Compression of Intense, High-Brightness Beams}

\section{Summary}

During the past twelve-month period the results of our highly successful experimental work on longitudinal space-charge waves and of the theoretical studies on thermal equilibrium and image effects in bunched beams have been brought to fruition and published in refereed journals (twelve articles, including five Physical Review Letters). A major event was the publication of the book, Theory and Design of Charged Particle Beams, in September 1994 [A1]. Three new experimental projects have been started - measurements of energy spread, resistive-wall instability, and design of magnetic quadrupoles, dipoles, and general layout for the lattice of the electron recirculator. The first results are very encouraging. Particularly exciting is the successful demonstration of slow-wave amplitude growth and fast-wave decay in the very difficult resistive-wall experiment, which our critical peers in the field had considered an almost impossible task. An overview of our study of the transport and longitudinal compression of intense, high-brightness beams and the results of theoretical work during this whole funding cycle will be given in an invited talk at the International Symposium on Heavy Ion Inertial Fusion, Princeton, NJ, September 6-9, 1995 [C10]. The experimental aspects of this research, such as longitudinal compression experiments, spacecharge wave experiments, and longitudinal instability experiments, will be presented in an invited talk at the Advanced Beam Dynamics Workshop on the Space-Charge Dominated Beam Transport and Applications of High Brightness Beams, Bloomington, IN, October 11-13, 1995 [C11].

\section{Experimental Research}

\subsection{Space-charge wave experiments}

During the past year we led our research on localized space-charge waves to a successful conclusion and started the first phase of our program on longitudinal instability. In addition to our previous PRL papers on the generation of space-charge waves and the measurements of the $\mathrm{g}$-factor, a third paper on reflection and transmission of space-charge waves at bunched beam ends has been published in Physical Review Letters [B11]. This paper reflects our continuous effort during last year to investigate theoretically the mechanism and conditions for reflection. The study of localized space-charge waves has led to a new beam diagnostic technique. A paper summarizing this technique has been recently published in Review of Scientific Instruments [B5]. Our research on space-charge waves has generated considerable interest in the accelerator community. Invited talks were given at the University of Michigan, Cornell University, Tsinghua University in Beijing, Institute of High Energy Physics of China, and at the 1995 PAC conference. An invited review paper on this subject has recently been published in International Journal of Modern Physics B [B12]. 


\subsection{Energy spread measurements}

Experimental work on measuring the distribution in longitudinal kinetic energy is in progress. Preliminary results were presented at the BEAMS'94 Conference [D1]. Measurements have been made on the density profiles using a phosphor screen and the longitudinal energy spread using a parallel plate energy analyzer. Analysis of the experimental results is in progress.

\subsection{Resistive-wall instability experiment}

Our study on longitudinal beam instability produced interesting experimental results during the current grant year after experiencing problems with resistive tube misalignment, system noise, etc. Because of the expected difficulties of such an experiment, many experts had doubted that our research would produce any meaningful results. However, our successful experiments have clearly demonstrated the growth of slow waves and the decay of fast waves. The experimental setup consisted of our short-pulse electron beam injector, a glass tube with a length of $0.96 \mathrm{~m}$ and a coated resistance of $5.4 \mathrm{k} \Omega$, a $1.4 \mathrm{~m}$ focusing solenoid, and diagnostics. In the experiment, electron beams of 3-8 keV, 30-80 mA, and about 100 ns in duration were passed through a resistive wall tube, and perturbations to generate slow or fast waves were launched at the center of these beams. Two current monitors at the entrance and the exit of the resistive tube were used to measure the growth and decay of the perturbations. The experiment showed that the amplitude of localized slow waves does not grow as much as expected from the conventional growth rate formula. A paper reporting our findings and current status of this research was presented at the $1995 \mathrm{PAC}$ conference.

\subsection{Design studies for electron recirculator}

A short magnetic quadrupole lens ("quad") was designed with the help of a commercial package for magnetic field calculations. The lens will be the main focusing element in a future electron recirculator; it consists of a two-sided flexible printed circuit to be wrapped around the transport pipe. To check the design and the code, a scaled-up (6x approx.) quad was built and the magnetic field components measured with a Hall probe at different radial distances from the lens axis. A pair of Helmholtz coils was used to balance the vertical component of the earth's magnetic field. There was excellent agreement between measured and calculated fields. The design proved to yield an axially integrated magnetic field whose linearity deviated from the average by less than $1 \%$ at a radial distance equal to $70 \%$ of the quad radius. This is more than adequate for the parameters of the electron beam in the recirculator. The work was reported at the $1995 \mathrm{PAC}$ conference.

The design of the mounts for the quads and for the bending/correcting printed circuit dipoles has been completed. The main parameters (dimensions, number of quads, dipoles and diagnostics) for the lattice in the recirculator have also been calculated. A preliminary study of the injector design using a Panofsky quadrupole is underway. A test of transverse matching of the injector will be performed soon. 


\section{Theoretical Research Progress}

\subsection{Theory and design of charged particle beams}

A major event was the publication of M. Reiser's book in the Wiley Series in Beam Physics and Accelerator Technology in September 1994 [A1]. It had been "in the works" for many years and incorporates the key results of experimental and theoretical research (behavior of space charge dominated beams, thermodynamic equilibrium, and emittance growth of nonstationary beams) that has been supported under Task A.

\subsection{Equilibrium in bunched beams}

We have completed theoretical work on the state of thermal equilibrium in bunched beams, and have applied the results to a new design for if linear accelerators and to current losses in existing and future accelerators. Thermal equilibrium density profiles were found numerically in three dimensions with axial symmetry and were related to experimental parameters, as was done previously for unbunched beams and for bunched in one dimension [B1]. Our results on equilibrium density profiles and current losses were be published in Physics of Plasmas [B10], and our proposal for a new design for rf linear accelerators has just been published in Physical Review Letters [B7]. Previous work on equilibrium in bunched beams has also been published [B8]. A paper on the properties of a zero-temperature bunched beam in a cylindrical was published in Particle Accelerators [B9].

\subsection{Design of optimal beam transport and matching systems}

The objective of this work is the determination of the optimal lens settings to transport and match a particle beam. Optimal in this sense typically means the minimization of emittance growth through the channel. Results for an axisymmetric continuous beam have been obtained and published [D2]. Work on methods of optimization for beams with ellipsoidal symmetry and possibly bunched beams is in progress. This work forms a major part of C.K. Allen's doctoral dissertation.

\subsection{Related Research at the Naval Research Laboratory}

The physics of the space-charge-limited beams in the University of Maryland Transport Experiment can be inherently nonlinear and, therefore, an analytic description is often not straightforward. The numerical simulation tools developed at the Naval Research Laboratory (I. Haber, NRL) have therefore been extensively employed in interpreting the experimental data, as well as in examining the underlying nonlinear physics.

Good agreement has been obtained in recent comparisons between simulation and experimental data on both the overall bunch dynamics, as well as many aspects of the propagation of a perturbation on the bunch. Some, as yet unresolved, difference between the codes and experiment were encountered in examining bunch-end reflection of the perturbation. The simulations were also able to explain the observation that the longitudinal dynamics are surprisingly insensitive to a transverse mismatch. In addition, a one-dimensional picture of the longitudinal dynamics of a space-charge dominated bunch was developed which extends the 
work of C.K. Allen, et al. on the self fields of a space-charged dominated bunch to bunches which are much longer than their diameter.

An additional aspect to the NRL program has been the extension of PIC numerical techniques to the examination of bunches which have the very small energy spreads that are characteristic of the Maryland experiments. These techniques are being used to complement the experiments by $\mathrm{N}$. Brown et al. to measure the growth in longitudinal beam temperature by examining non-collisional mechanisms by which the transverse beam energy can be coupled to the longitudinal direction. Simulations of the longitudinal resistive-wall instability are also under way in parallel with the acquisition of data from this experiment.

A more detailed exposition of the current NRL program is available in the progress reports on that program.

\section{Papers and Presentations Resulting from this Research}

\section{A. Books}

1. M. Reiser, Theory and Design of Charged Particle Beams, New York: John Wiley \& Sons, Inc., 1994.

\section{B. Papers in Refereed Journals}

1. M. Reiser and N. Brown, "Thermal Distribution of Relativistic Particle Beams with Space Charge", Phys. Rev. Lett. 71 (18), 2911 (1993).

2. J.G. Wang, H. Suk, D.X. Wang, and M. Reiser, "Determination of the Geometry Factor for Longitudinal Perturbations in Space-Charge Dominated Coasting Beams," Phys. Rev. Lett. 72 (13), 2029 (1994).

3. D.X. Wang, J.G. Wang, and M. Reiser, "Restoration of Rectangular Pulse Shape After Edge Erosion for a Space-Charge Dominated Electron Bunch," Phys. Rev. Lett. 73 (1), 66 (1994).

4. H. Suk, M. Reiser, J.G. Wang, and D.X. Wang, "Experimental Verification of the Smooth-Approximation Theory for Space-Charge Dominated Beam in a Periodic Focusing Channel," J. Appl. Phys. 76 (7), 3970 (1994).

5. J.G. Wang and M. Reiser, "Beam Diagnostics with Localized Space-Charge Waves," Rev. Sci. Instrum. 65 (11), 3444 (1994).

6. N. Brown and M. Reiser, "Solution to the Stationary Longitudinal Envelope Equation", Part. Accel. 43 (4) 231 (1994).

7. M. Reiser and N. Brown, "Proposed High-Current rf Linear Accelerators with Beams in Thermal Equilibrium", Phys. Rev. Lett. 74 (7), 1111 (1995).

8. C.K. Allen, N. Brown, and M. Reiser, "Image Effects for Bunched Beams in Axisymmetric Systems," Part. Accel. 45, 149 (1994).

9. C.K. Allen and M. Reiser, "Zero-Temperature Equilibrium for Bunched Beams in Axisymmetric Systems", to be published in Part. Accel. 48 (4), 1995.

10. N. Brown and M. Reiser, "Thermal Equilibrium of Bunched Charged Particle Beams", Phys. Plasmas 2 (3) (March 1995). 
11. J.G. Wang, D.X. Wang, H. Suk, and M. Reiser, "Reflection and transmission of Space-Charge Waves at the Ends of a Space-Charge Dominated Electron Bunch," Phys. Rev. Lett. 74 (1b), 3153 (1995).

12. J.G. Wang and M. Reiser, "Space-Charge Waves in a Space-Charge Dominated Beam, " Int. J. of Mod. Phys. B. 9 (12), 1409 (1995).

13. H. Suk, J.G. Wang, and M. Reiser, "Space-Charge Solitary Wave in a ChargedParticle Beam in a Resistive-Wall Channel," submitted for publication to Phys. Plasmas.

\section{Invited Talks}

1. J.G. Wang, "Studies of Longitudinal Dynamics of Space-Charge Dominated Beams," at the Laboratory of Plasma Studies (LPS) Colloquium, Cornell University, Ithaca, NY, April 13, 1994.

2. M. Reiser, and J.G. Wang, Course Lectures for "Introductions to Theory and Design of Charged Particle Beams," Particle Accelerator School, Bloomington, IN, June 20 to July $1,1994$.

3. M. Reiser, "Beam Physics Design Strategy for a High-Current RF Linac," International Conference on Accelerator-Driven Transmutation Technologies and Applications, Las Vegas, NV, July 25-29, 1994.

4. J.G. Wang, "Longitudinal Dynamics of Space-Charged Dominated Beams," at the Accelerator Lab., Dept. of Modern Applied Physics, Tsing-Hua University, Beijing, China, September 2, 1994.

5. J.G. Wang, "Longitudinal Dynamics of Space-Charged Dominated Beams," at the Institute of High-Energy Physics, Beijing, China, September 13, 1994.

6. M. Reiser, "Charged Particle Beams for Advanced Accelerator Applications," Invited Lectures at Beijing, Xian, and Chengdu, China, October 3-14, 1994.

7. M. Reiser, "Charged Particle Beams for Advanced Accelerator Applications," Electrophysics Seminar, Institute for Plasma Research, University of Maryland, October 28, 1994.

8. M. Reiser, "Charged Particle Beams for Advanced Accelerator Applications," Plasma Physics Colloquium, Columbia University, NYC, January 22, 1995.

9. J.G. Wang, "Studies of Localized Space-Charge Waves in Space-Charge Dominated Beams," presented at the 1995 Particle Accelerator Conference and International Conference on High-Energy Accelerators, Dallas, TX, May 1-5, 1995.

10. M. Reiser, "Physics of Intense Charged Particle Beams for Heavy Ion Inertial Fusion," Invited Talk, 1995 International Symposium on Heavy Ion Inertial Fusion, Princeton, NJ, Sept. 6-9, 1995.

11. J. G. Wang, "Experimental Studies on Longitudinal Dynamics of Space-Charge Dominated Beams," to be presented at the Advanced Beam Dynamics Workshop on Space-Charge Dominated Beam Transport and Applications of High Brightness Beams, Bloomington, IN, Oct. 11-13, 1995. 


\section{Papers in Conference Proceedings}

1. N. Brown, M. Reiser, H. Suk and J. G. Wang, "Effects of Beam and Channel Parameters on Energy Spread in Periodically Focused Electron Beams", Proceedings of the 10th International Conference on High-Power Particle Beams, $\mathrm{p} 548$.

2. C.K. Allen, S.K. Guharay, and M. Reiser, "Optimal Control of Low-Energy Particle Beams", Conf. Proceedings Beams '94, San Diego, June 20-24, 1994.

3. M. Reiser, "Beam Physics Strategy for a High-Current RF Linac," in Proceedings of the International Conference on Accelerator-Driven Transmutation Technologies and Applications, Las Vegas, July 1994.

4. M. Reiser, "Design of Equipartitioned High-Current RF Linacs," in Proceedings of the 17th International Linac Conference, Tsukuba, Japan, August 1994.

5. J.G. Wang and M. Reiser, "Localized Space-Charge Waves for Beam Diagnostics," in Proceedings of the 17th Int. Linac Conf., Tsukuba, Japan, August 21-26, 1994.

\section{E. Papers Presented at Meetings}

1. M. Reiser, J.G. Wang, H. Suk, and D.X. Wang, "Determination of the Geometry Factor for Longitudinal Perturbations in Space-Charge Dominated Coasting Beams," presented at the 1994 Annual Meeting of the Division of Physics of Beams, APS Spring Meeting, Crystal City, VA, April 18-22, 1994.

2. J.G. Wang, D.X. Wang, H. Suk, and M. Reiser, "Study of the Edge Effect of Bunched Beams on Space-Charge Waves," presented at the 1994 Annual Meeting of the Division of Physics of Beams, APS Spring Meeting, Crystal City, VA, April 18-22, 1994.

3. D.X. Wang, J.G. Wang, and M. Reiser, "Reconstruction of Rectangular Pulse Shape for a Space-Charge Dominated Beams," presented at the 1994 Annual Meeting of the Division of Physics of Beams, APS Spring Meeting, Crystal City, VA, April 18-22, 1994.

4. H. Suk, M. Reiser, J.G. Wang, and D.X. Wang, "Experimental Verification of the Smooth Approximation Theory for a Space-Charge Dominated Beam in a Periodic Focusing Channel," presented at the 1994 Annual Meeting of the Division of Physics of Beams, APS Spring Meeting, Crystal City, VA, April 18-22, 1994.

5. J.G. Wang, M. Reiser, and H. Suk, "Studies of Waves and Instabilities in SpaceCharge Dominated Beams," presented at the 36th Annual Meeting, APS Division of Plasma Physics, Minneapolis, MN, November 7-11, 1994. 


\title{
Task B Progress Report
}

\author{
Study of High Brightness Beam Generation in Pseudospark: Devices
}

\section{Summary}

This report summarizes the status of both the high-voltage pulse-line driven and the low-voltage pseudospark experiments for the period June 1, 1994 to May 31, 1995. The goal of this research was to determine if the very high brightness electron beams generated in low voltage pseudospark devices $(<50 \mathrm{kV})$ could be scaled to the energies and current associated with high power pulse-line accelerators [1].

\section{High-Voltage Pseudospark Experiment}

\subsection{Long pulse with current limiting resistors}

In this experiment, a six-gap pseudospark assembly with current limiting resistor (200 $\mathrm{ohm})$ was used [2]. High brightness $\left(>10^{10} \mathrm{~A} / \mathrm{m}^{2} \mathrm{rad}^{2}\right)$ electron beams were generated at approximately $170 \mathrm{kV}$. Ejected electron-beam diameters in the range $1.3 \mathrm{~mm}$ were observed. The high-energy component of the electron beam was generated in a 20-30 ns burst immediately before the voltage collapse. The effective emittance was measured and found to be in the range $30-90 \mathrm{~mm}-\mathrm{mrad}$. A beam intercepting emittance mask was used and a double Rogowski energy range probe was built. This probe could measure simultaneously the incident and transmitted current.

This device worked extremely well for voltages around $170 \mathrm{kV}$. But at operating voltages higher than this value, the assembly had problems associated with field-emission induced breakdowns, low-fill gas pressure, and the components' high voltage compatibility.

\subsection{Table-top experiments}

Because extension of the successful long pulse pseudospark experiment to higher voltages was not easily accomplished due to the previously mentioned problems, a table-top experiment was conducted to investigate two things specifically: a suitable working gas and the thickness of the insulator. It was determined that helium, hydrogen and nitrogen had satisfactory operating pressures and the thickness of the insulator did not influence electron beam generation [3].

\section{Low-Voltage Pseudospark Experiments}

\subsection{Study of pseudospark breakdown voltage}

Breakdown voltage characteristics of single-gap and multi-gap pseudosparks were investigated experimentally. Simple empirical scaling laws that could be applied universally were determined for breakdown voltage characteristics. For the single-gap pseudospark, the breakdown voltage was found to be a function of the product of $p^{2} d D$ for $d<3 D$, and a 
function of $p d$ for $d>3 D$, where $D$ is the diameter of the hollow-cathode cavity, $d$ is the anode-cathode gap, and $p$ is the gas pressure. For the multi-gap pseudospark, however, the breakdown voltage is only a function of the product $p^{2} d D$. Results of this stidy are detailed in papers [4] and [5].

\subsection{Post-acceleration and propagation of pseudospark-produced electron beam}

The electron beam from a pseudospark propagating in a low-pressure gas was accelerated by an induction linac system. The beam transport characteristic in the gas filled drift tube was then determined by measuring beam profiles at various axial distances. Results are detailed in paper [6].

\section{Papers and Presentations Resulting from this Research}

1. K. Ramaswamy "High power, high brightness electron beam generation in a pseudospark discharge," Ph.D Dissertation in progress.

2. K. Ramaswamy, W.W. Destler, Z. Segalov and J. Rodgers, "Characterization of electron beams generated in a high-voltage pulse-line-driven pseudospark discharge," J. Appl. Physics 75 (9), 1994.

3. K. Ramaswamy, W.W. Destler and J.Rodgers, "An experimental investigation into the effect of the floating electrode on the breakdown characteristic of a multigap pseudospark system," to be published.

4. M. J. Rhee and C. J. Liu, "Generalized breakdown voltage characteristic of the pseudospark," Appl. Phys. Lett. 65, 3314 (1994).

5. C. J. Liu and M. J. Rhee, "Experimental Investigation of Breakdown Voltage Characteristics of Single-gap and Multi-gap Pseudospark," to be published in IEEE Trans. Plasma Sci., Apr. (1995).

6. C. J. Liu and M. J. Rhee, "Experimental Study of Post-Acceleration and Transport of a Pseudospark-Produced Electron Beam," in Proceedings of the 1993 Particle Accelerator Conference, Washington, DC, May 17-20, 1993, edited by S. T. Corneliussen, p. 688.

7. M. J. Rhee and C. J. Liu, "Investigation of the Hollow Cavity Effects on the Breakdown Voltage Characteristic of a Single-Gap Pseudospark Device," IEEE Conference RecordAbstract, 1994 IEEE International Conference on Plasma Science, p. 86 (1994).

8. C. J. Liu and M. J. Rhee, "Study of Transport of the Electron Beam Produced by a Pseudospark," IEEE Conference Record-Abstract, 1994 IEEE International Conference on Plasma Science, p. 156 (1994).

9. C. J. Liu and M. J. Rhee, "Measurement of Beam Currents in the Hollow Cavity of a Pseudospark," IEEE Conference Record-Abstract, 1994 IEEE International Conference on Plasma Science, p. 175 (1994). 


\section{Task C Progress Report \\ Study of Microwave Sources and Parameters Scaling \\ for High-Frequency $\mathrm{TeV}$ Linear Colliders}

\section{Summary}

Significant progress has been made toward the demonstration of a two-cavity, frequencydoubling, gyroklystron amplifier that is designed for $1.5 \mu \mathrm{sec}$ output pulses, with $>100 \mathrm{MW}$ peak power at a frequency of $17 \mathrm{GHz}$. Such a demonstration would surpass any projections of performance possible with conventional klystrons. The gyroklystron circuit will be coaxial. Simulation of the co-axial gyroklystron performance indicate that efficiency will be $35 \%$; improved design of the gyroklystron output cavity is being pursued with a goal of achieving $40 \%$ efficiency. Further efficiency enhancement by use of a depressed collector is also possible.

The modulator for powering the gyroklystron has been successfully upgraded from a 450 $\mathrm{kV}, 400 \mathrm{~A}$ capability to a $500 \mathrm{kV}, 750 \mathrm{~A}$ capability. The pulse flattop time has been increased from $1.0 \mu \mathrm{s}$ to $1.5 \mu \mathrm{s}$. The major parts of the gyroklystron, including the electron gun and the microwave output window, are being fabricated and should be completed during summer 1995. Assembly of the full experiment is expected in the fall.

An interim experimental study of third harmonic operation of a frequency-tripling gyroklystron was carried out with output power at the $1 \mathrm{MW}$ level. The study of the instabilities which were observed in this experiment will be useful in advanced gyroklystron designs. For example, a design study of a three-cavity gyroklystron is underway with frequency doubling in each stage and with output frequency in the range $35-40 \mathrm{GHz}$. Collider frequency-scaling analysis continues to show the advantage of operating at higher frequency especially if the overall length of the collider is limited.

\section{Theoretical Analysis}

\subsection{Frequency Scaling}

Frequency scaling laws for microwave sources required for future linear colliders have been extended. The attainable performance of both klystrons and gyroklystrons in the frequency range from $15 \mathrm{GHz}$ to $40 \mathrm{GHz}$ has been analyzed. It was shown, for example, that to produce a frequency doubling in gyroklystrons one has to accompany this with transition from operation in the $\mathrm{TE}_{02}$-mode to the $\mathrm{TE}_{03}$-mode. Then, the maximum microwave power allowed by the microwave breakdown restriction will remain almost unchanged. At the same time, if the frequency doubling is accompanied by a doubling in the pulse compression ratio, the optimal number of gyroklystrons will be reduced and the optimal accelerating gradient will be increased approximately by a factor of 2 . Also, a conceptual design for a three-cavity gyroklystron with quadrupling of the drive frequency has been analyzed that permits one to generate high-power microwave radiation in the range of $35-40 \mathrm{GHz}$ without the need for cryogenically cooled solenoids.

Plans for the future include modification of the theory of frequency scaling for microwave tubes accounting for practical restrictions on the total length of a TeV-class linear collider. 
Table 1: Circuit Dimensions.

\begin{tabular}{|ll|ll|}
\hline Input cavity: & & Output cavity: \\
\hline Mode & $\mathrm{TE}_{01}$ & Mode & $\mathrm{TE}_{02}$ \\
Frequency & $8.50 \mathrm{GHz}$ & Frequency & $17.0 \mathrm{GHz}$ \\
Quality factor & 74 & Quality factor & 510 \\
$R_{o}$ & $3.330 \mathrm{~cm}$ & $R_{o}$ & $3.330 \mathrm{~cm}$ \\
$R_{i}$ & $1.830 \mathrm{~cm}$ & $R_{i}$ & $1.830 \mathrm{~cm}$ \\
$R_{1}$ & $1.052 \mathrm{~cm}$ & $R_{2}$ & $3.651 \mathrm{~cm}$ \\
$L_{1}$ & $2.286 \mathrm{~cm}$ & $R_{L}$ & $3.580 \mathrm{~cm}$ \\
& & $L_{t 1}$ & $3.000 \mathrm{~cm}$ \\
& & $L_{2}$ & $0.640 \mathrm{~cm}$ \\
\cline { 1 - 1 } Drift section: & & $L_{t 2}$ & $1.000 \mathrm{~cm}$ \\
Length & $9.000 \mathrm{~cm}$ & $\theta$ & 1.15 degrees \\
\hline
\end{tabular}

These plans also include a more detailed analysis of the gyroklystrons projected performance in the frequency range from $20 \mathrm{GHz}$ to $40 \mathrm{GHz}$.

\subsection{Amplifier Designs}

The primary goal in the last year was to design a high efficiency, coaxial, second harmonic gyroklystron operating at $17.1 \mathrm{GHz}$. We chose as our basic design a smooth walled output cavity operating in the $\mathrm{TE}_{02}$ mode. A schematic of the circuit is shown in Fig. 1 (Fig. 1a: input cavity, Fig. 1b: output cavity), with parameters given in Table 1 . The nonlinear upand down-tapers were chosen to minimize mode conversion. Mode competition studies [1] indicated that efficiency is greatly reduced if the third harmonic interaction is allowed to compete with the second. To eliminate this competition, we chose the inner and outer radii of the output cavity to make the third harmonic beam-wave coupling as small as possible. We then optimized efficiency with respect to cavity length, quality factor, and magnetic field profile. So far we have achieved a design efficiency of $35 \%$ with a $7 \%$ axial velocity spread. We will continue optimizing this design, with a goal of $40-50 \%$ efficiency.

An important consideration for gyroklystrons is stability against the excitation of parasitic modes. Previously, stability has been determined from the linear start-oscillation current; i.e., the start oscillation current in the absence of the operating mode. While such calculations are fast and relatively straightforward, they tend to underestimate the start current. Thus, in the past year we developed a fully nonlinear multi-mode code to compute the start current in the presence of the operating mode. It turns out that for the design shown in Fig. 1 , there is a $\mathrm{TE}_{01}$ mode $(8.73 \mathrm{GHz}, \mathrm{Q}=44)$ with a linear start current near $100 \mathrm{~A}$ and a $\mathrm{TE}_{12}$ mode $(8.94 \mathrm{GHz}, \mathrm{Q}=45)$ with a linear start current of about the same value. This linear start current is significantly lower than the nominal beam current of $500 \mathrm{~A}$. However, with the operating mode present our multimode code indicated that the start current is 2.2 $\mathrm{kA}$ and $5.2 \mathrm{kA}$ for the $T E_{01}$ and $T E_{12}$ modes, respectively. Thus, the multi-mode analysis indicates that the design shown in Fig. 1 is stable to parasitic modes as long as the operating mode is present. Of course, there are always startup issues: it is, in principal, possible for 
a)

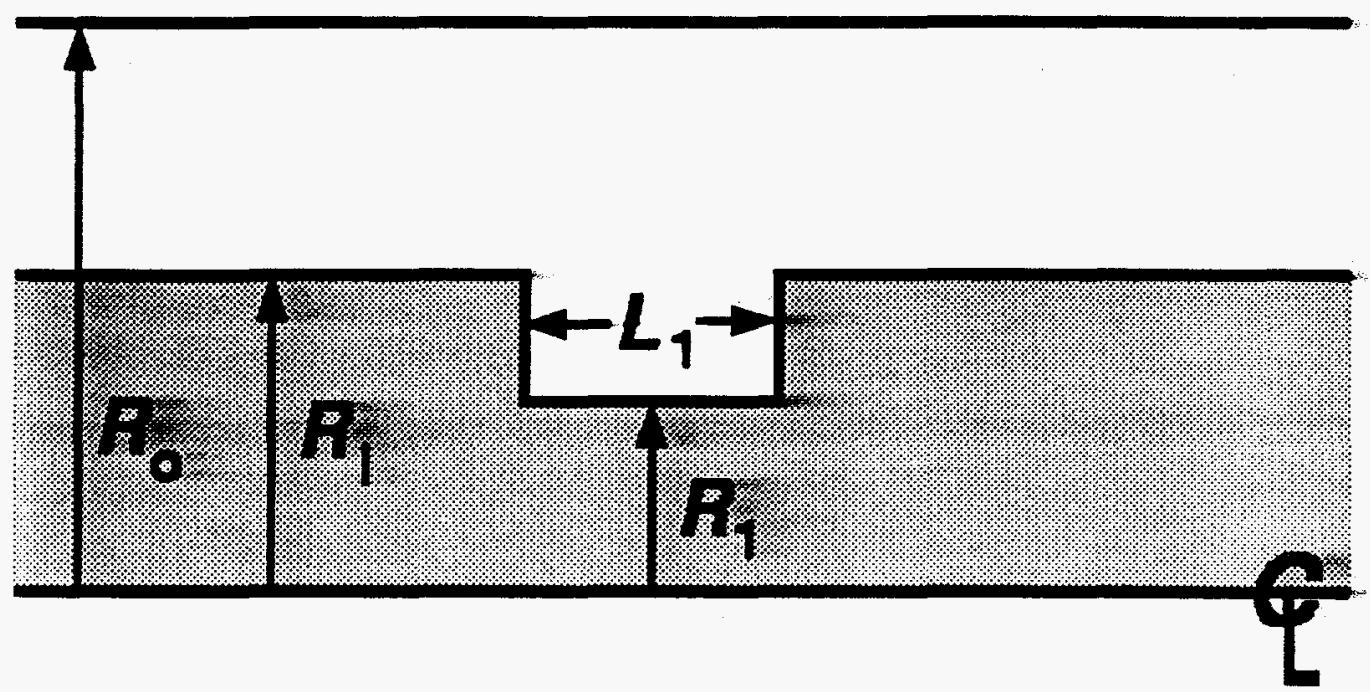

b)

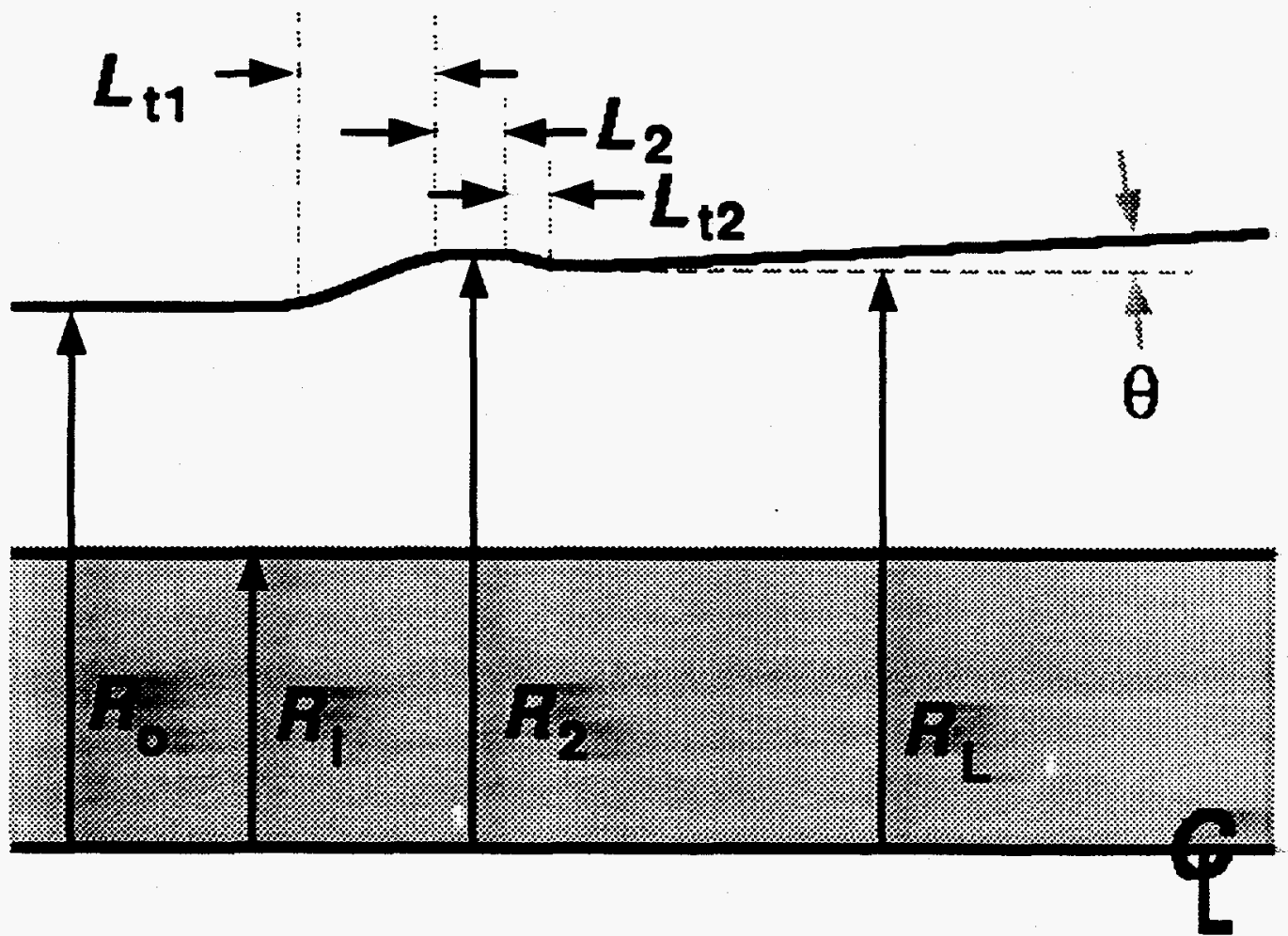


the $\mathrm{TE}_{01}$ or $\mathrm{TE}_{12}$ modes to grow to a large value before the operating mode can be excited, and end up suppressing it. However, because the beam is prebunched we, do not consider this to be likely.

In addition to our effort on the gyroklystron, work continues on the gyrotwystron. We designed a second harmonic gyrotwystron. We also completed a detailed write up of the multi-mode analysis of the gyrotwystron, which resulted in the submission of two papers to Physics of Plasmas [2,3].

\section{Microwave Amplifier Experiments}

Two microwave amplifier configurations were tested in the previous year. The first was a third harmonic two-cavity gyroklystron, which was expected to produce about $10 \mathrm{MW}$ of power with $10 \%$ efficiency near $30 \mathrm{GHz}$ (according to simulations). This tube was constructed by replacing the output cavity of a second harmonic tube with one that resonated in the $\mathrm{TE}_{03}$ mode. The maximum tube amplifier power achieved was only slightly above $1 \mathrm{MW}$ and was limited by output cavity instabilities. The tube was also extremely sensitive to beam parameter variations and the pulse width was only a few hundred nanoseconds. From our studies of 1st - 3rd harmonic gyroklystrons, we have found a general narrowing of the pulse width as the harmonic number increases that is symptomatic of the increased parameter sensitivity of harmonic operation. This increased sensitivity was observed in virtually every parameter sweep we performed.

The final configuration that we tested was a second harmonic gyrotwystron. The theoretical efficiency at the optimal point was simulated to be about $24 \%$. The second-harmonic tube experienced more mode competition than the fundamental gyrotwystron tube we tested last year and could not operate at the theoretical optimal point. The best repeatable results obtained included a peak power of about $12 \mathrm{MW}$ with $11 \%$ efficiency. There were occasional shots with higher power ( $>16 \mathrm{MW})$, indicating that better performance was possible if the mode-competition problems were alleviated. The results of this experimental effort are detailed in a paper which was submitted to the Journal of Applied Physics.

While we had ideas for how to improve the performance of the two tubes described above, we discontinued the experiments to prepare for the $100 \mathrm{MW}$ amplifier configuration described in the following section.

\section{MW System Design and Construction}

In the past year we have made substantial progress towards upgrading our facilities to accommodate the $100 \mathrm{MW}$ level experiments. Most significantly, the modulator has been modified and tested to the level of $500 \mathrm{kV}, 750 \mathrm{~A}$. This represents a considerable enhancement over the previous $450 \mathrm{kV}, 400 \mathrm{~A}$ system. In addition, all of the output current in the new modulator can be converted into beam current in the new single-anode electron gun, compared to only $250 \mathrm{~A}$ in the old double-anode gun that employed a resistive divider to power the modulation anode. A new series of dummy loads inside the modulator will be used to absorb excess modulator current in $200 \mathrm{~A}$ increments for cases when the beam current is reduced via a lower cathode temperature. The remaining mismatch can easily be accommodated by the system. The principle hardware modifications involved in this 
upgrade were an increase in the number of pulse forming networks (PFNs) from 4 to 8 , the construction of an additional PFN tank and a new high voltage tank, and an improved arrangement of high voltage components with reduced stray capacitance.: As a result of the last modification, the measured risetime $(0-100 \%)$ of the new voltage pulse is $1.5 \mu \mathrm{s}$, compared to $2.0 \mu \mathrm{s}$ in the old system, and the usable flattop time has increased from $1.0 \mu \mathrm{s}$ to $1.5 \mu \mathrm{s}$. The reduction in stray capacitance also decreases the magnitude of reverse voltage imposed on the switching thyratrons, which will improve their reliability and lifetime. We have also successfully modified the cathode filament transformer and associated controller circuits to accommodate the larger cathode heater power requirements $(60 \mathrm{~V}$ and $25 \mathrm{~A})$ of the new electron gun. At present we are adding a re-designed oil cooling system and output electrical connection socket to prepare for the installation of the gun.

We are also in the process of completing work on a variety of support systems associated with the new experiments. The magnetron-based input microwave source has been upgraded to produce $150 \mathrm{~kW}, 8.56 \mathrm{GHz}, 2.5 \mu \mathrm{s}$ long pulses. The microwave hardware and diagnostic system to bring the magnetron power to the gyroklystron has been designed and the parts are currently on order. In addition, a new power supply for the magnet coil located at the axial position of the cathode (gun coil) has been installed. Finally, we have procured a new computer for our screen room and we are in the process of upgrading our data acquisition software.

Progress on the beam transport system has been made in a variety of areas. A custom vacuum pumping manifold, to be located between the beam dump and output window, has been completed. It can accommodate up to three $60 \mathrm{l} / \mathrm{s}$ ion pumps (although we will start with only two at this location, with two others pumping on the electron gun), a turbo pump for bakeout purposes, ion and RGA gauges, and gas admission ports. All of this auxiliary vacuum hardware is already on hand. Five inch diameter aluminum oxide output windows have been ground and metalized by an outside source; we have also completed the metallic parts for two complete window assemblies and are anticipating brazing the windows into them in the near future. A large nonlinear uptaper, to be located between the output window and the microwave diagnostics, has been designed and an aluminum mandrel with the appropriate contour is currently being constructed by an outside vendor. This will be used to electroform the actual taper in copper. A large iron-core electromagnet, which will produce a $300-400 \mathrm{G}$ transverse magnetic field over a five inch diameter by 5 inch long region at the end of the beam dump (to ensure that no on-axis electrons strike the output window), has been constructed in-house and is ready for installation. Modifications to the magnet table to support the new beam transport system and associated radiation shielding are currently underway. A significant amount of effort has been directed towards designing the downtaper region between the electron gun and the microwave circuit. A detailed mechanical drawing of the region has been completed, including a finalized plan for positioning lossy dielectrics within the structure. We will be using carbon impregnated aluminum silicate (CIAS), to be manufactured in-house, as the lossy material. Raw material for these absorbers is currently on order. We are also producing detailed individual drawings for each of the metal parts associated with this downtaper; these will be primarily manufactured by an outside vendor. A task related to the downtaper involves a careful study of the dielectric properties (real and imaginary parts of the dielectric constant) of CIAS absorbers over a much wider frequency range $(2-20 \mathrm{GHz})$ than previously performed. We will also study the effect of modifications 
to the standard absorber manufacturing technique on dielectric properties. We anticipate being able to deliberately vary the dielectric properties of the absorbers along the length of the downtaper, to optimize the absorption of spurious modes as a function of position. This is necessary because the magnetic field and beam tunnel radius changes as the beam proceeds through the downtaper, which dramatically changes the frequencies and mode patterns of the oscillations.

The basic microwave circuit for the $\mathrm{TE}_{01}$ fundamental harmonic $8.56 \mathrm{GHz}$ experiment has been conceptually designed for some time. Recently, we have begun to devise a vacuum compatible version of the device. The input cavity will use a pair of input windows and coupling slots 180 degrees apart on the sidewall to excite the $\mathrm{TE}_{01}$ mode. The long-leadtime $80 \% \mathrm{BeO}-20 \% \mathrm{SiC}$ Ceralloy microwave absorbers for the drift tube walls have arrived and are in agreement with design specifications, and additional CIAS absorbers for use in the drift tube will be manufactured in the near future. We are continuing to theoretically study improved $\mathrm{TE}_{02}$ second harmonic output cavities, with a primary aim towards improved efficiency. Ku-band microwave hardware for cold-testing of the best concepts has been delivered.

The construction of the electron gun by Varian Associates was completed and the gun was received in April, 1994. However, the heater circuit in the emitter strip built by Semicon failed under test. Steps are being taken to correct the fault and rebuild the electron gun.

\section{Papers and Presentations Resulting from this Research}

1. G.S. Nusinovich, P.E. Latham, and O. Dumbrajs, "Theory of Relativistic Cyclotron Masers," Phys. Rev. E. 52 (1) 998 (1995).

2. P.E. Latham and G.S. Nusinovich, "Theory of Relativistic Gyro-Traveling Wave Devices," to be published in Physics of Plasmas.

3. P.E. Latham and G.S. Nusinovich, "Stability Analysis of Relativistic Gyro-Traveling Wave Devices," to be published in Physics of Plasmas.

4. P. E. Latham, W. Lawson, and V. Irwin, "The Design of a $100 \mathrm{MW}, \mathrm{Ku}$-Band Second Harmonic Gyroklystron Experiment," IEEE Trans. Plasma Sci. 22 (1994) 804.

5. H. W. Matthews, W. Lawson, J. P. Calame, M. K. E. Flaherty, B. Hogan, J. Cheng, and P. E. Latham, "Experimental Studies of Stability and Amplification in a Two-Cavity Second Harmonic Gyroklystron," IEEE Trans. Plasma Sci. 22 (1994) 825.

6. J. P. Calame, J. Cheng, P. E. Latham, W. Lawson, B. Hogan, H. W. Matthews, M. K. E. Flaherty, and C. D. Striffler, "Amplification Studies of a Two-Cavity Second Harmonic Gyroklystron with a Mixed-Mode Output Cavity," J. Appl. Phys. 75 (1994) 4721.

7. P. E. Latham, W. Lawson, V. Irwin, B. Hogan, G. S. Nusinovich, H. W. Matthews, and M. K. E. Flaherty, "High Power Operation of an X-Band Gyrotwistron," Phys. Rev. Lett. 72 (1994) 3730. 
8. J. P. Calame, J. Cheng, B. Hogan, W. Lawson, C. D. Striffler, P. E. Latham, and V. Irwin, "Measurements of Velocity Ratio in a 90 MW Gyroklystron Electron Beam," IEEE Trans. Plasma Sci. 22 (1994) 476.

9. M. K. E. Flaherty, W. Lawson, B. Hogan, H. W. Matthews, and J. P. Calame, "Operation of a K-Band Second Harmonic Coaxial Gyroklystron," J. Appl. Phys. 76 (1994) 4393.

10. W. Lawson, P. E. Latham, J. P. Calame, J. Cheng, B. Hogan, G. S. Nusinovich, V. L. Granatstein, and M. Reiser, "High Power Operation of Fundamental-Mode and Second Harmonic Gyrotwystrons," J. Appl. Phys. 78, 550 (1995).

11. J. Cheng, W. Lawson, J. P. Calame, P. E. Latham, V. L. Granatstein, and M. Reiser, "The Gyroklystron as a Possible RF Source for Future TeV Colliders," to be published in Proceedings of the 1994 Advanced Accelerator Concepts Workshop.

12. W. Lawson and P. Wilson, "Summary Report: RF (New/Novel Ideas) Part I: RF Sources," to be published in Proceedings of the 1994 Advanced Accelerator Concepts Workshop.

13. J. P. Calame, W. Lawson, J. Cheng, B. Hogan, P. E. Latham, M. Castle, V. L. Granatstein, and M. Reiser, "100 MW Gyroklystron Development for Linear Collider Applications," to be published in Proceedings of the 2nd International Workshop on Pulsed RF Sources for Linear Colliders (RF '94).

14. W. Lawson, J. P. Calame, J. Cheng, M. K. E. Flaherty, V. L. Granatstein, B. Hogan, V. Irwin, P. E. Latham, H. W. Matthews, G. S. Nusinovich, and M. Reiser, "Experimental Studies of High-Power Harmonic Gyroklystrons," Beams '94 Conference Proceedings, p. 264.

15. P. E. Latham, W. Lawson, V. Irwin, B. Hogan, G. S. Nusinovich, H. W. Matthews, and M. K. E. Flaherty, "Gyrotwistrons as a Source for Future Particle Accelerators," Beams '94 Conference Proceedings, p. 889.

16. W. Lawson, J. P. Calame, P. E. Latham, J. Cheng, V. L. Granatstein, and M. Reiser, "Experimental Design of 100 MW X-Band and Ku-Band Gyroklystrons," LINAC '94 Conference Proceedings, (in press).

17. W. Lawson, J. P. Calame, J. Cheng, M. Castle, P. E. Latham, B. Hogan, V. L. Granatstein, and M. Reiser, "Theoretical and Experimental Investigation of Gyrotron Amplifiers for Collider Applications," 1994 IEDM Tech. Digest, p. 247.

18. W. Lawson, J. P. Calame, J. Cheng, V. L. Granatstein, B. Hogan, and P. E. Latham, "Experimental Studies of 30 MW Fundamental Mode and Harmonic Gyro-amplifiers," 1994 Int. Conf. Infrared Millimeter Waves, October 1994, p. 421.

19. J. Cheng, W. Lawson, M. K. E. Flaherty, J. P. Calame, P. E. Latham, B. Hogan, and V. L. Granatstein, "Design of X-Band and Ku-Band 100 MW Gyroklystrons," 1994 Int. Conf. Infrared Millimeter Waves, October 1994, p. 423. 
20. M. K. E. Flaherty, W. Lawson, J. Cheng, J. P. Calame, B. Hogan, P. E. Latham, and V. L. Granatstein, "Design and Experimental Results of Coaxial Circuits for Gyroklystron Amplifiers," 1994 IEEE Int. Conf. Plasma Science, June 1994, p. 203:

21. J. P. Calame, W. Lawson, J. Cheng, M. K. E. Flaherty, B. Hogan, P. E. Latham, V. Irwin, H. W. Matthews, M. Reiser, and V. L. Granatstein, "Design of $8.5 \mathrm{GHz}$ Fundamental and $17 \mathrm{GHz}$ Second Harmonic Gyroklystron Experiments with $100 \mathrm{MW}$ Output Power Capability," 1994 IEEE Int. Conf. Plasma Science, June 1994, p. 111.

22. W. Lawson, J. P. Calame, J. Cheng, M. Castle, P. E. Latham, and B. Hogan, "Design of Fundamental Mode and Second-Harmonic High-Power Coaxial Gyroklystrons for Collider Applications," Bull. Am. Phys. Soc. 39 (1994) 1743.

23. V. L. Granatstein, G.S. Nusinovich, J. Calame, W. Lawson, J. Cheng. P. Latham and M. Reiser, "Prospects for Developing Microwave Amplifiers to Drive Multi-TeV Linear Colliders," Bull. Am. Phys. Soc. 40 (1995) p. 1105; to be published in the Proceedings of the 1995 Particle Accelerator Conference and International Conference on High-Energy Accelerators.

24. J. Calame, W. Lawson, J. Cheng, B. Hogan, M. Castle, V. Granatstein, and M. Reiser, "Design of $100 \mathrm{MW}$, Two-Cavity Gyroklystrons for Accelerator Applications," Bull. Am. Phys. Soc. 40 (1995) p. 1106; to be published in the Proceedings of the 1995 Particle Accelerator Conference and International Conference on High-Energy Accelerators.

25. W. Lawson, G. Saraph, J. P. Calame, J. Cheng, M. Castle, B. Hogan, M. Reiser, V. Granatstein, and H. Metz, "Design of Three-Cavity Coaxial Gyroklystron Circuits for Linear Collider Applications," Bull. Am. Phys. Soc. 40 (1995) p. 1106; to be published in the Proceedings of the 1995 Particle Accelerator Conference and International Conference on High-Energy Accelerators. 